IP Periodica Polytechnica

Mechanical Engineering

62(2), pp. 110-117, 2018

https://doi.org/10.3311/PPme.10950

Creative Commons Attribution (i)

RESEARCH ARTICLE

\section{Experimental and FE Modeling of Mixed-Mode Crack Initiation Angle in High Density Polyethylene}

\author{
Abdelwahab Zerrouki ${ }^{1 *}$, Abdelkader Boulenouar ${ }^{1}$, Mohamed Mazari ${ }^{1}$, \\ Mohamed Benguediab ${ }^{1}$
}

Received 26 April 2017; accepted after revision 03 January 2018

\begin{abstract}
In this paper, an experimental and a numerical analysis were carried out using High density polyethylene (HDPE). Sheets with an initial central crack (CCT specimens) inclined with a given angle are investigated and compared to the loading direction. The kinking angle is experimentally predicted and numerically evaluated under mixed mode $(I+I I)$, as a function of the strain energy density (SED) around the crack-tip, using the Ansys Parametric Design Language (APDL).According to the experimental observations and numerical analysis, the plan of crack propagation is perpendicular to the loading direction. Moreover, as suggested by Sih in the framework of linear elastic fracture mechanics (LEFM), the minimum values Sminof the factor $S$ are reached at the points corresponding to the crack propagation direction. These results suggest that the concept of the strain energy-density factor can be used as an indicator of the crack propagation direction.
\end{abstract}

\section{Keywords}

strain energy density, mixed mode, HDPE, crack initiation

\section{Introduction}

Thanks to many advantages which the high-density polyethylene (HDPE) has, it is highly used in the networks of drinking water. However, since 2003, several water distributers noted premature failures of connections in HDPE, in particular, when the pipeline is subjected to bending or stretching.

As known, the major source of failure of structural components is crack growth for such reason, defects and pre-cracks may be introduced in HDPE pipelines during installation, repair or by accident. Crack propagation was not considered to predict its trajectory. Nevertheless, at present, studying crack propagations' direction has been made possible by Finite Element Method (FEM), and the prediction of crack initiation angle in components is accessible by the fracture mechanics approaches, according to these approaches, the fracture process is assumed to be initiated from the pre-existing defects cited previously [1]. Therefore, it is necessary to develop a procedure that allows the prediction of crack initiation angle and the propagation direction in HDPE.

In linear elastic fracture mechanics, the various fracture criteria for cracks subjected to mixed mode loading have been introduced for the determination of the propagation direction and the critical stress, such as maximum tangential stress criterion [2, 3-5], maximum principal tangential stress criterion [3], maximum strain criterion [6-7], and strain energy density criterion [3,8]. All these criteria are almost postulated that crack initiation will occur at the crack tip and propagate towards the radial direction.

Sih's [3, 9-11] strain energy density criterion takes the strain energy density to be investigated of an element around the crack tip as the starting point and the strain energy density factor as a basic parameter. It is then postulated that crack initiationwill occur at the crack tip in a radial direction along which the strain energy density factor, $\mathrm{S}$, is minimum, and the crack will begin to propagate when the factor, $\mathrm{S}$, reaches some critical value.

The strain energy density criterion was validated experimentally and numerically on brittle materials [8, 12-20] and ductile materials [21-23]. In the framework of the large deformations, $[24,25]$ used this criterion on rubber materials to predict the initial crack orientation under mode-I and mixed mode loadings. The SED approach has been successfully used by Torabi 
et al. [26], Berto et al. [27] and Campagnolo et al. [28] to assess the fracture strength of different materials, characterized by different control volumes and subjected to wide combinations of static loading [29-32]. Moreover, it has been successfully employed for the fatigue strength of welded joints [33-34] and notched components [35, 36]. As shown by Lazzarin et al. [37], the SED can be easily evaluated numerically through finite element analysis by using coarse meshes, and it allows automatically to take into account higher order terms and three-dimensional effects $[38,39]$. These considerations are among the main advantages of the SED approach.

The objective of this paper is to present an experimental and numerical modeling of crack initiation angle for ductile fracture of HDPE, under mixed mode (I+II). Using the Ansys Parametric Design Language (APDL), the crack direction is evaluated as a function of the minimum strain energy density $(\mathrm{dW} / \mathrm{dV})_{\min }$ around the crack tip. The results obtained by numerical approach are compared with those obtained in experiments.

\section{Strain energy density theory}

The SED fracture criterion locally focuses on the continuum element ahead of the crack,it is based on the notion of weakness or severity experienced by the local material. Failure occurs when a critical amount of strain energy $\mathrm{dW}$ is accumulated within the element volume $\mathrm{dV}$ and the crack is then advanced incrementally in the corresponding direction $[3,40]$. The strain energy density function $(d W / d V)$ is assumed to have the following form

$$
\frac{d W}{d V}=\frac{S}{r}
$$

Where $S$ is the strain energy density factor and $r$ is the distance from the crack tip. The minimum of the strain energy density factor $S_{\text {min }}$ around the crack tip determines the likely direction of crack propagation.

The strain energy density can be determined directly from the relationship.

$$
\frac{d W}{d V}=\int_{0}^{\varepsilon_{i j}} d \sigma_{i j} \cdot d \varepsilon_{i j}
$$

Where $\sigma_{i j}$ and $\varepsilon_{i j}$ are the stress and strain components respectively [41].

The strain energy per unit volume $d W / d V$ can be further decomposed into two parts:

$$
\frac{d W}{d V}=\left(\frac{d W}{d V}\right)_{d}+\left(\frac{d W}{d V}\right)_{v}
$$

$(d W / d V)_{d}$ represents the distortional strain energy per unit volume, corresponding to the deviatoric stress tensor that is associated with distortion (shape change) of an element and is responsible for macroyielding and the creation of slip planes or microcracks. $(d W / d V)_{v}$ represents the part of the strain energy per unit volume associated with dilatation (volume change) and is responsible for macrofracture (crack growth) and the creation of the cleavage planes which are perpendicular to the direction of tension.

The computed discrete values for $S$ are fitted with approximation function which enables simple determination of the local minimum. The strain energy density function has several local minimums around the crack tip, where the global minimum is not necessarily the true solution, as it can be observed from Fig. 1.

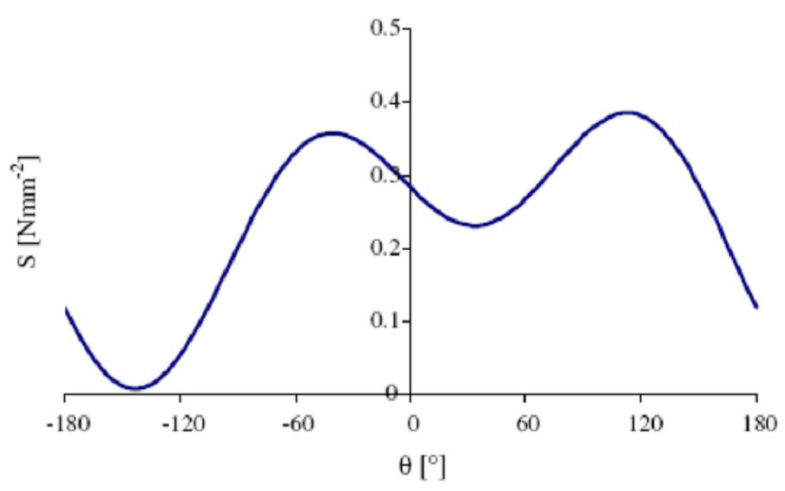

Fig. 1 Strain energy density factor $S$ as a function of the angle $\theta$

The minimum of strain density function $S_{\min }$ can be found numerically by incrementalsearch for a local minimum in possible crack extension directions $\theta_{i}$ in the range $\pm \pi$ around the crack tip [42].

Fajdiga et al.[42] used the position of integration points to define the corresponding angle of calculated strain energy density and strain energy density factor $S$ around the crack tip. In this study, the minimum strain energy density $(d W / d V)_{\min }$ is computed by introducing a ring of elements around the crack tip. At each crack increment, the crack direction is evaluated as a function of the angle between the centre of the element and the crack axis (Fig. 2).

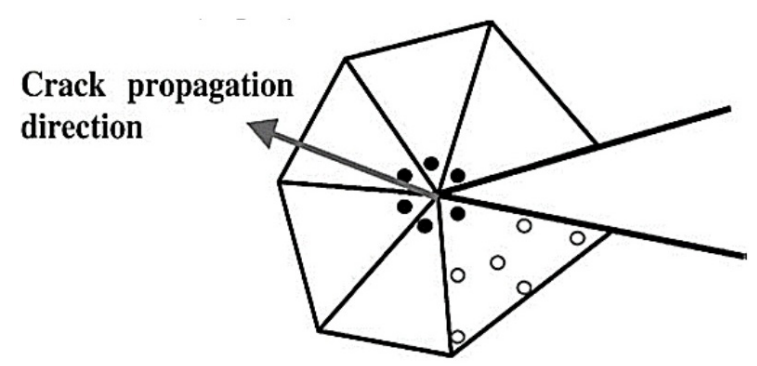

Fig. 2 Direction of propagation using the minimum strain energy density

\section{Mixed mode fracture tests}

\subsection{Materials, specimens, tests}

The experiments were carried out in CHIALI Group using HDPE. Fracture tests were performed using specimens containing an inclined central crack introduced by a razor blade.

The dimensions of these specimens are: length $h=120 \mathrm{~mm}$, width $w=75 \mathrm{~mm}$ and thickness $B=4 \mathrm{~mm}$ (Fig. 3 ). The considered crack length is a $=20 \mathrm{~mm}$ with four orientations defined by the angle $\alpha=\left\{0^{\circ}, 30^{\circ}, 45^{\circ}, 60^{\circ}\right\}$. Specimens were loaded 
in a uniaxial direction under controlled load $\mathrm{F}=10 \mathrm{KN}$ with a strain rate of $v=50 \mathrm{~mm} / \mathrm{min}$, but a mixed mode (I+II) could be induced around the crack tip because of the crack inclination. Fig. 3 shows the geometry of the center cracked specimens used in fracture tests under mode-I and mixed mode loadings.
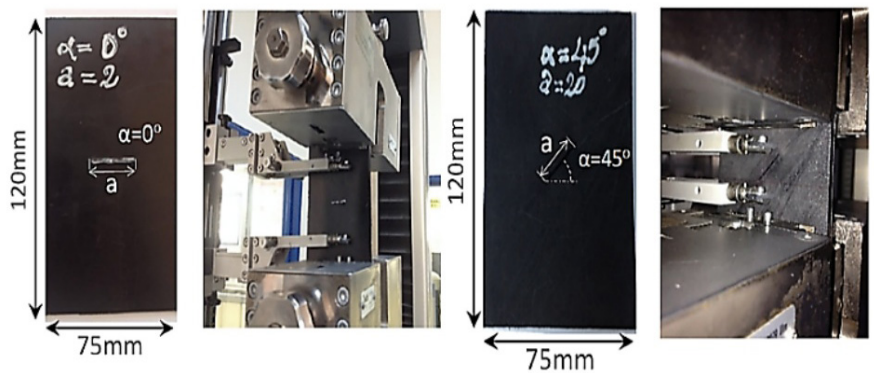

Fig. 3 Geometry of the Centre Cracked Tension specimens (CCT) used in fracture tests

\subsection{Crack initiation angle}

The crack initiation angle $\theta_{0}$ is the direction in which the crack propagates from the original crack (Fig. 4(a)). For different $\alpha$, the value of $\theta_{0}$ is predicted by each fracture test. Fig. 4(b) shows the crack initiation angle evaluated in this study (Table1).

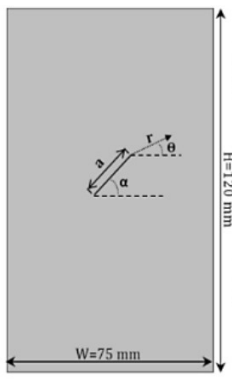

a)

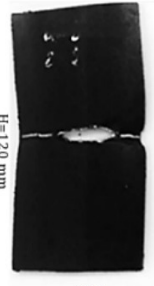

$\alpha=0^{\circ}$

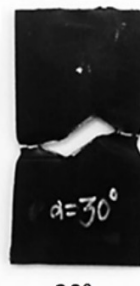

$\alpha=30^{\circ}$

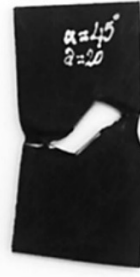

$\alpha=45^{\circ}$

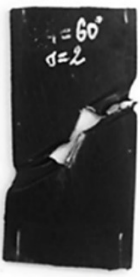

$\alpha=60^{\circ}$ b)

Fig. 4 (a) Description of crack imitation angle $\theta$,

(b) Crack initiation obtained from fracture tests

Table 1 Crack initiation angle $\theta_{0}\left({ }^{\circ}\right)$ obtained from fracture tests

\begin{tabular}{lcc}
\hline Specimen code & Crack inclined angle $\alpha\left(^{\circ}\right)$ & Crack initiation angle $\theta_{0}\left({ }^{\circ}\right)$ \\
\hline 1 & $0^{\circ}$ & $-5^{\circ}$ \\
2 & $30^{\circ}$ & $-45^{\circ}$ \\
3 & $45^{\circ}$ & $-64^{\circ}$ \\
4 & $60^{\circ}$ & $83^{\circ}$ \\
\hline
\end{tabular}

\section{Finite elements study}

\subsection{Model and meshing}

The geometry of the centre cracked plate $(120 \mathrm{~mm} \times 75 \mathrm{~mm})$ with an initial crack $(a=20 \mathrm{~mm})$ is considered for 2-Dimensional finite element analysis. The pre-existing central crack is inclined to the horizontal axis with angle $\alpha=\left\{0^{\circ}, 30^{\circ}, 45^{\circ}, 60^{\circ}\right\}$. The FE calculation was achieved by gradually increasing of the displacements (d) applied to the nodes located at the top of the plate.

All the above mentioned fracture tests were numerically simulated using the ANSYS ${ }^{\circ}$ finite element code [43].
For the mesh generation of the cracked plate, the element type 'PLANE183' is used, as shown in Fig. 5(a).

It is a higher order two dimensional, 8-node element having two degrees of freedom at each node (translations in the nodal $\mathrm{x}$ and $\mathrm{y}$ directions), quadratic displacement behavior and the capability of forming a triangular-shaped element, which is required at the crack tip areas.

Due to the singular nature of the stress field in the vicinity of the crack, the singular elements proposed by Barsoum [44] are considered at each crack tip area. Fig. 5(b) shows the typical finite element mesh used for numerical analysis.

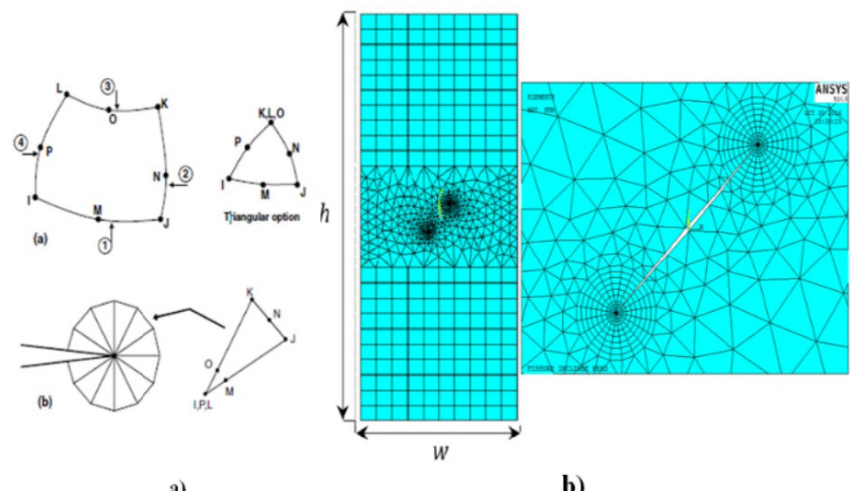

Fig. 5 (a) Element types used in meshing

(b) Example of a selected meshing $\left(\alpha=45^{\circ}\right)$

The material properties used in this study were those corresponding to the stress-strain curve obtained from experimental tensile tests obtained by Blaise [45].

The stress-strain curve is modelled by elastic-plastic behavior with multi-linear isotropic hardening according to the experimental plastic curve $[46,47]$.

The rings of the elements surrounding the tip of the crack were employed. This mesh will be used in order to determine the strain energy density in these elements thus to determine the kinking angle $\theta$ in the direction for which this energy density is minimal $(d W / d V)_{\min }$.

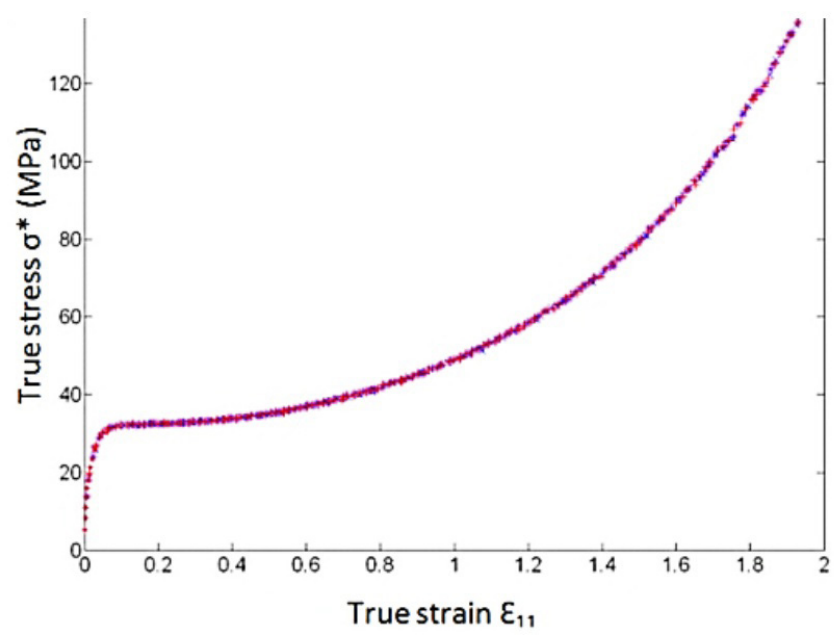

Fig. 6 The stress-strain curve obtained from experimental tensile tests [45] 
Fig. 7 illustrates the description of the parameters: $r, \alpha$ and $\theta$. Where: $r$ is the distance from the crack-tip, $\alpha$ is the crack inclination angle and $\theta$ is the initial crack propagation.

The specifications of the crack tip mesh and a close up view for crack inclination angle $\alpha=45^{\circ}$ are shown in Fig. 8. In this figure, ' $r_{i}$ ' represents the distance between the crack tip and the center of the element ' $c$ '.

\section{Results and discussion}

\subsection{Strain energy density}

The obtained results are traced for several values of the radius $r_{i}$ and for four orientations of initial crack $\alpha=0^{\circ}, 30^{\circ}$, $45^{\circ}$ and $60^{\circ}$ (Fig. 9).

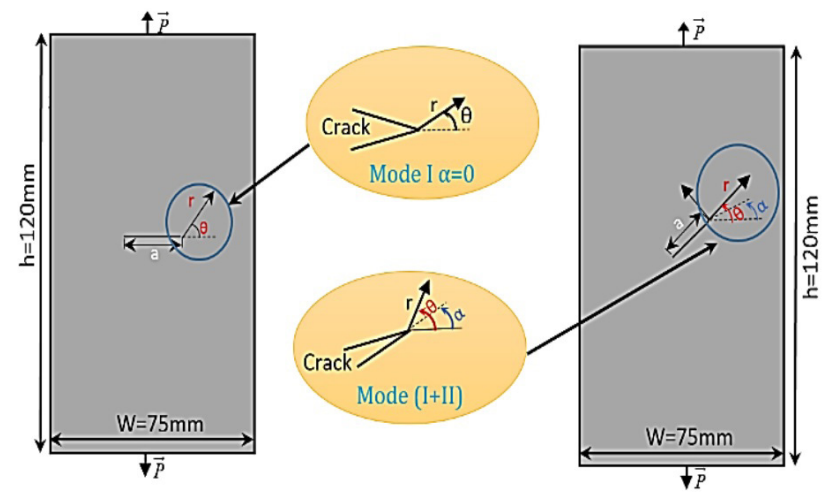

Fig. 7 Description of the parameters $\mathrm{r}, \alpha$ and $\theta$
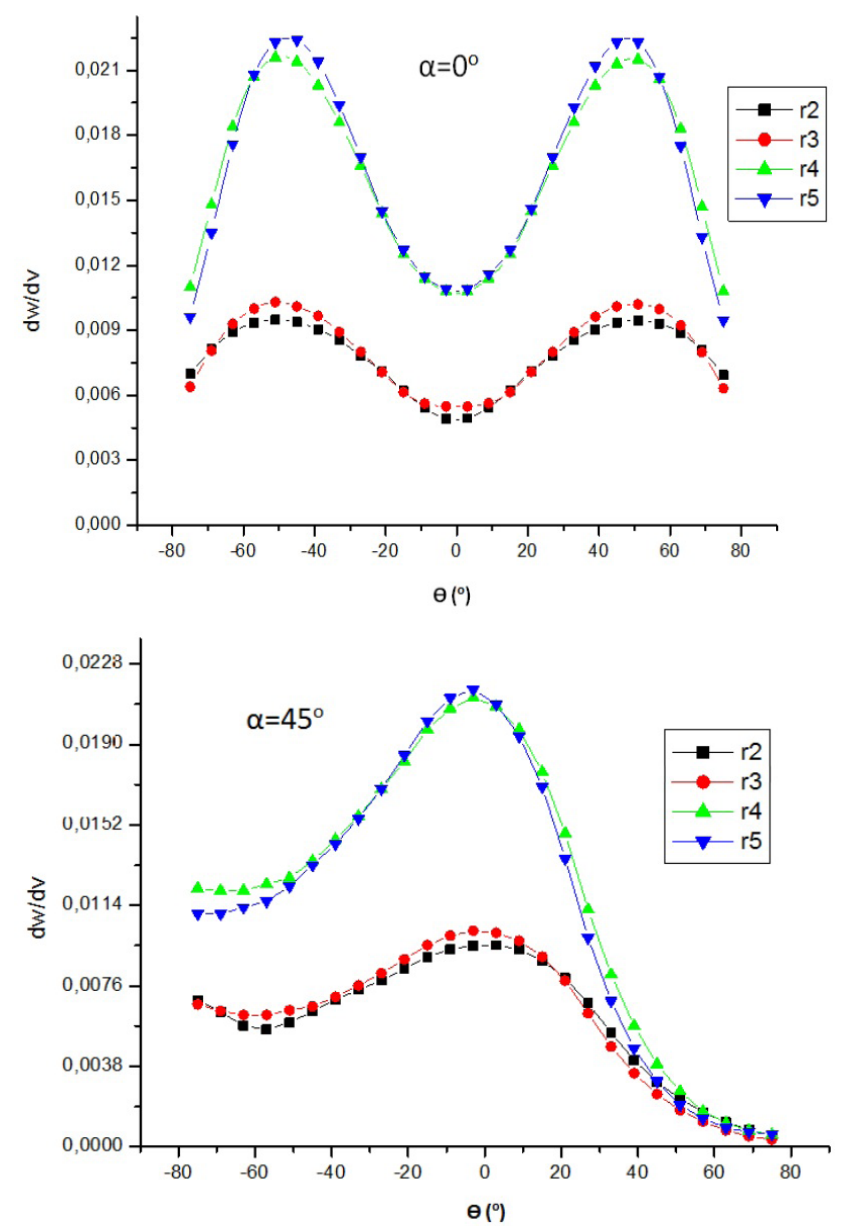

These figures highlight that, out of the core region surrounding the crack tip (in our caser $\left.\geq r_{1}\right)$, the minimum of $(d W / d V)$ is reached for a constant value independently of distance $r$. The angle $\theta_{0}$ corresponds to the horizontal direction perpendicular to the loading.

In general, a material element is subjected to both distortion and dilatation. Distortion and dilatation vary in proportion, depending on the load history, location, and nonuniformity in stress or energy fields. For the macrocrack under tension, the macrofracture coincides with the direction in which $(d W / d V)$ $>(d W / d V)_{d}$ and macroyielding with the direction in which $(d W / d V)_{d}>(d W / d V)_{v}$. In the case of 2-D analysis, the continuum mechanics solution of the stress problem shows that the

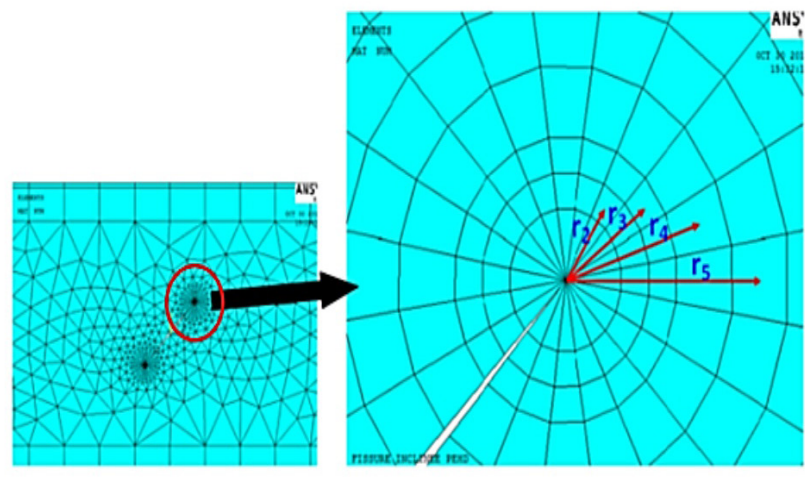

Fig. 8 Ring of elements around the crack tip
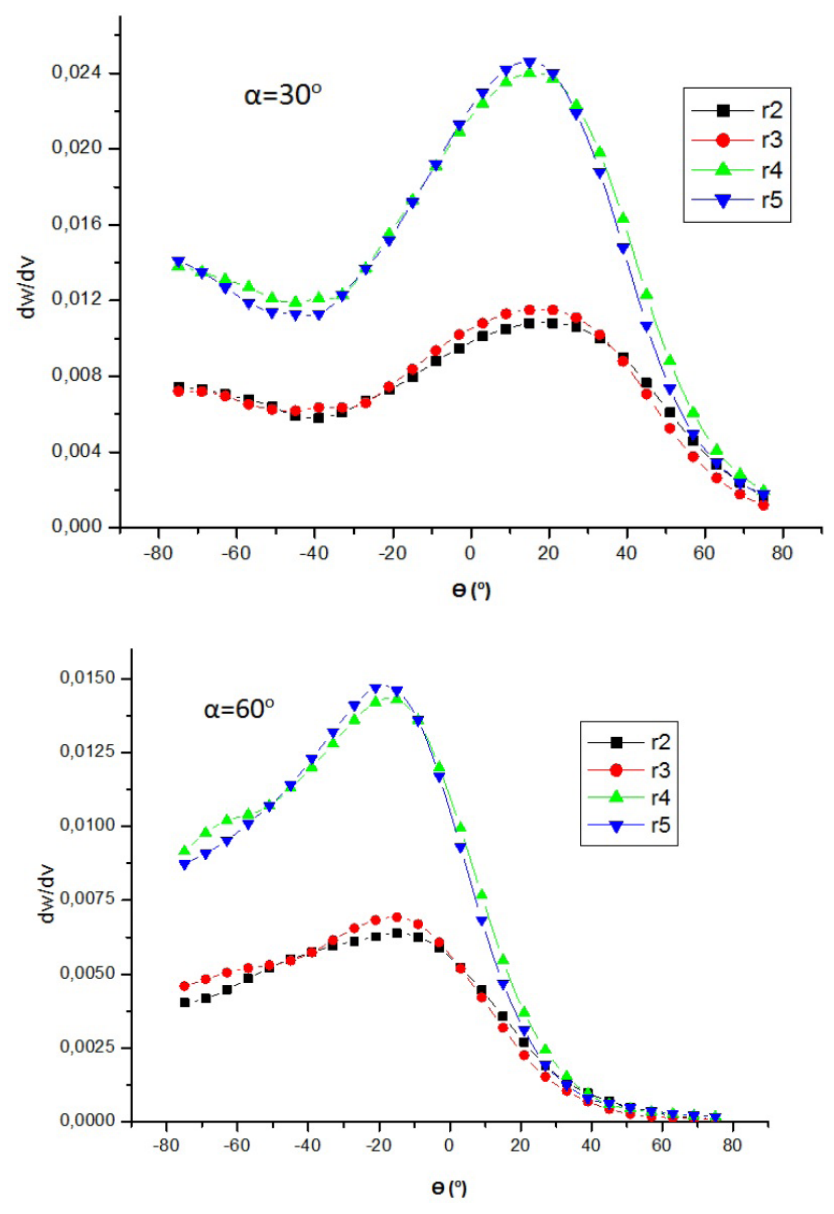

Fig. 9 Evolution of $d W / d V$ as a function of $\theta$ for several values of the radius $r$ (with $\alpha=0^{\circ}, 30^{\circ}, 45^{\circ}$ and $60^{\circ}$ ) 
principal stresses $\sigma_{1}$ and $\sigma_{2}$ are equal $\left(\sigma_{1}=\sigma_{2}\right)$ in the element ahead crack, under this condition the greatest change in volume occurs $\left((d W / d V)_{\mathrm{v}}>(d W / d V)_{\mathrm{d}}\right)$.

That means the domination of the macrodilatation, which is responsible to the cleavage process in the plane perpendicular to the loading direction [41].

The relative local minimum of $d W / d V$ corresponds to large change in volume and is identified with the region dominated by macrodilatation leading to fracture i.e. the appearance of cleavage planes perpendicular to the direction of tension.

The angle values obtained numerically are compared with those predicted experimentally. The obtained result shows a good correlation between the two approaches. Table 2 summarizes the crack initiation angle $\theta_{0}$ of fracture tests and FE analysis for different crack inclination angles $\alpha$.

Table 2 Comparison between crack initiation angle $\theta_{0}\left({ }^{\circ}\right)$ obtained from fracture tests and numerical results (for $\mathrm{r} 2$ )

\begin{tabular}{lcc}
\hline Crack inclination & \multicolumn{2}{c}{ Crack initiation angle $\theta_{0}\left({ }^{\circ}\right)$} \\
\cline { 2 - 3 } angle $\alpha\left(^{\circ}\right)$ & Fracture tests & SED criterion \\
\hline 0 & -5 & 0 \\
30 & -45 & -40 \\
45 & -64 & -56 \\
60 & -83 & -78 \\
\hline
\end{tabular}
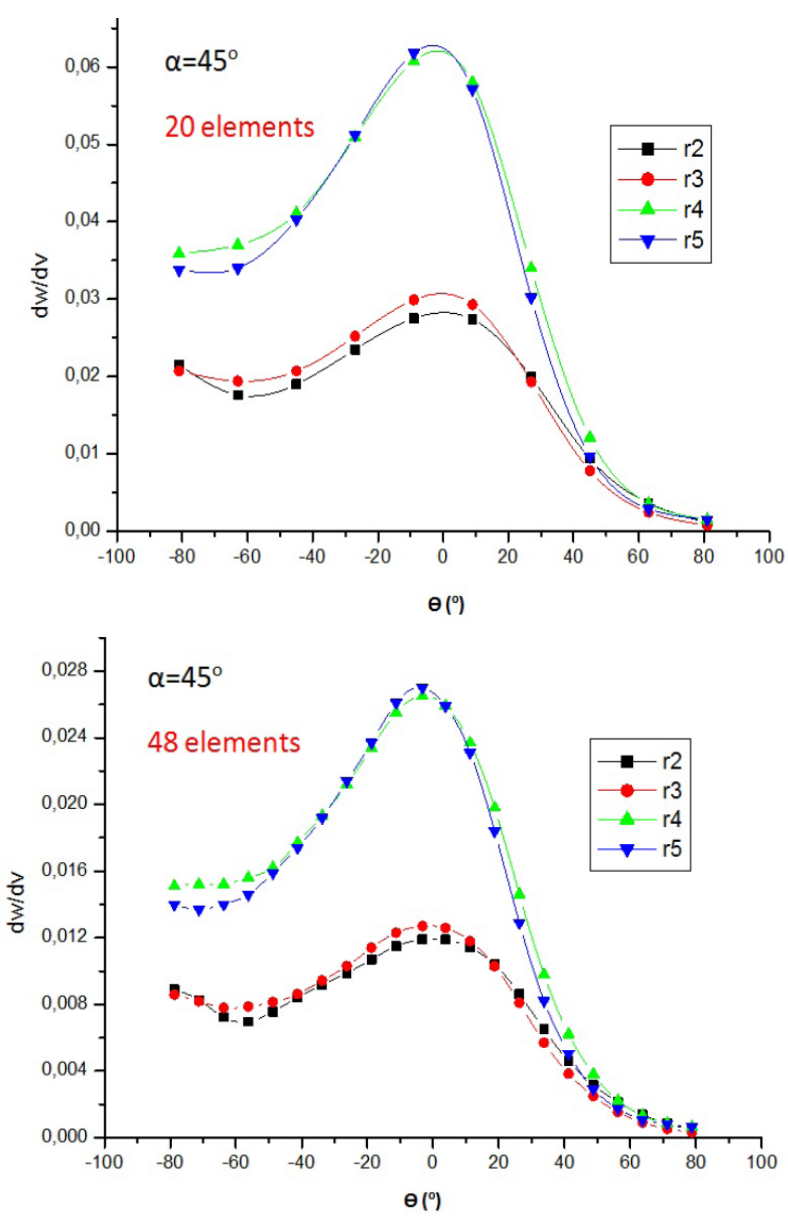

\subsection{Effect of elements number surrounding the crack tip}

For the strain energy density criterion, the precision is strongly related to the number of elements surrounding crack tip zone [35]. For this purpose, we examined the influence of the mesh size (or number of the elements) on the strain energy density variation. For that, the density $(d W / d V)$ is evaluated for different number of elements surrounding the crack tip. Inthis study, the numbers of elements considered are 20, 36, 48 and 60 (Fig. 10).

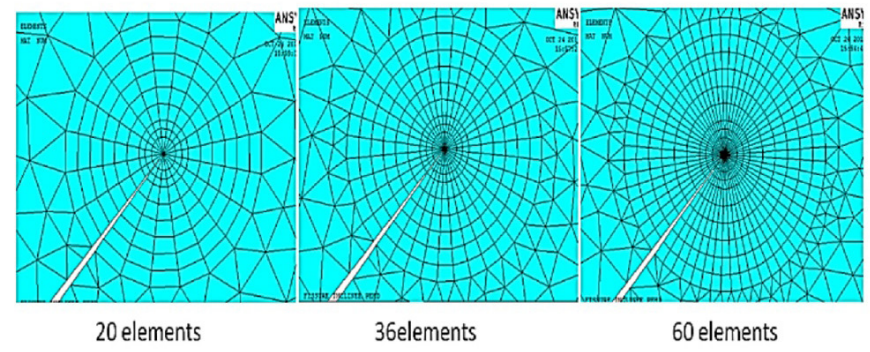

Fig. 10 Elements' sizes around the crack tip

For different number of elements surrounding crack tip zone and for several values of the radius r, Fig. 11 illustrates the evolution of the strain energy density $(d W / d V)$ as function of the initial angle of propagation $\theta$. The results obtained show that the precision is related to the elements sizes around the crack tip.
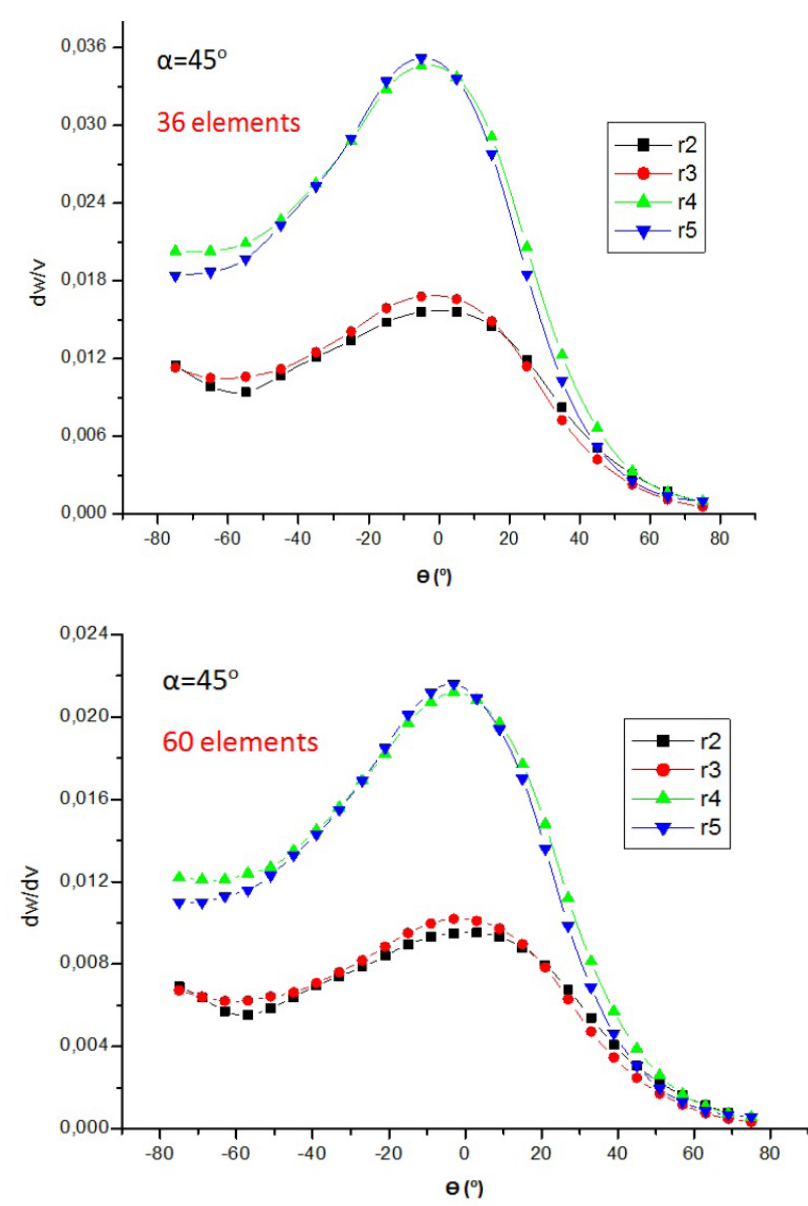

Fig. 11 Influence of meshing on the evolution of $d W / d V$ (for $\alpha=45^{\circ}$ ) 
To better show the influence of the elements sizes around the crack tip on the determination of initial angle of crack propagation $\theta_{0}$, Fig. 12 illustrates the variation of angle $\theta_{0}$ as a function of number of elements of elements surrounding the crack tip for various distances.

The curves obtained show that more there will be elements around the crack tip; more the crack direction $\theta_{0}$ at each crack increment length and the final path of crack propagation will be precise.

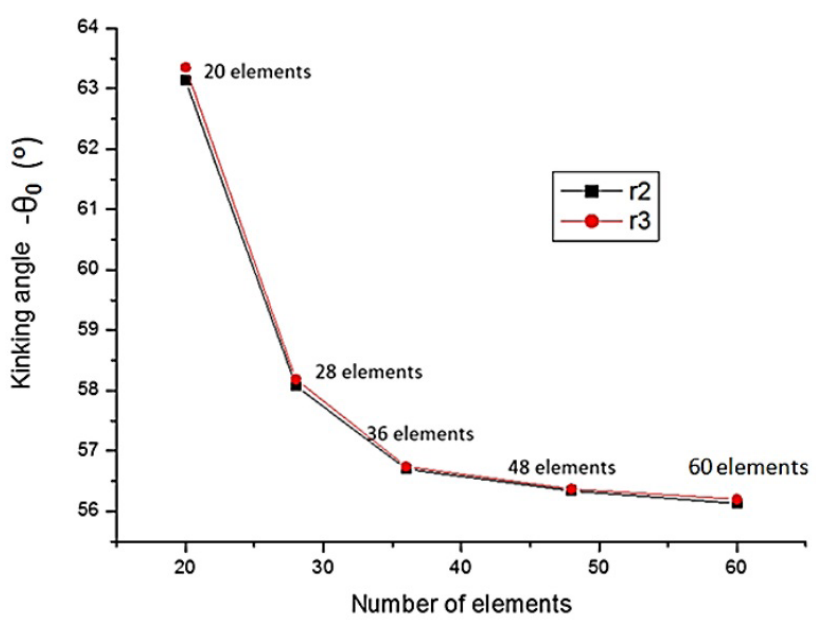

Fig. 12 Influence of meshing on the determination of the angle $\theta_{0}$

$$
\text { (for } \alpha=45^{\circ} \text { ) }
$$

\section{Conclusion}

The study has been conducted to analyze and simulate the initial crack propagation angle in HDPE, under mixed mode (I+II). Using the Ansys Parametric Design Language (APDL), the strain energy density approach is investigated. For various crack inclined angle, the kinking angle is evaluated as a function of the Minimum Strain Energy Density (MSED) around the crack tip. The obtained results allow us to deduce the following conclusions:

- The quarter-point singular elements proposed by Barsoumare used to consider the singularity of stress and deformations fields at crack tip.

- Out of a core region surrounding the crack tip, the minimum of SED is reached for a constant value independently of distance $r$. The obtained results show a convenient agreement between experimental and numerical approach.

- The minimal value of SED, corresponding to the direction of crack propagation, is always reached in the plan perpendicular to the loading axis, independently of the initial crack orientation.

- The value of the angle of initial crack direction is related to the number of the elements surrounding the crack tip.

- Consequently, the SED approach, developed in the linear elastic fracture problems, could be extended to highly non-linear deformable materials as an indicator of the crack propagation direction.

\section{References}

[1] Elmeguenni, M., Naït-Abdelaziz, M., Zaïri, F., Gloaguen, J. M. "Fracture characterization of high-density polyethylene pipe materials using the J-integral and the essential work of fracture." International Journal of Fracture. 183, pp. 119-133. 2013. https://doi.org/10.1007/s10704-013-9848-X

[2] Erdogan, F., Sih, G. C. "On the crack extension in plates under plane loading and transverse shear." Journal of Basic Engineering. 85, pp. 519-527. 1963.

https://doi.org/10.1115/1.3656897

[3] Sih, G. C. "Strain energy-density factor applied to mixed mode crack problems." International Journal of Fracture. 10, pp. 305-321. 1974. https://doi.org/10.1007/BF00035493

[4] Chang, K. J. "Further studies of the maximum stress criterion on the angled crack problem." Engineering Fracture Mechanics. 14, pp. 125-142. 1981. https://doi.org/10.1016/0013-7944(81)90022-9

[5] Maiti, S. K., Smith, R. A. "Comparison of the criteria for mixed mode brittle fracture based on the preinstability stress-strain field." International Journal of Fracture. 23, pp. 281-295. 1983. https://doi.org/10.1007/BF00020696

[6] Wu, H. C. "Dual failure criterion for plane concrete." Journal of the Engineering Mechechanics Division. 100, pp. 1167-1181. 1974.

[7] Chang, K. J. "On the maximum strain criterion - a new approach to the angled crack problem." Engineering Fracture Mechanics. 14, pp. 107124. 1981.

https://doi.org/10.1016/0013-7944(81)90021-7

[8] Theocaris, P. S. "A higher-order approximation for the T-criterion of fracture in biaxial fields." Engineering Fracture Mechanics. 19, pp. 975-991. 1984.

https://doi.org/10.1016/0013-7944(84)90144-9

[9] Sih, G. C., Macdonald, B. "Fracture mechanics applied to engineering problems-Strain energy density fracture criterion." Engineering Fracture Mechanics. 6, pp. 361-386. 1974.

https://doi.org/10.1016/0013-7944(74)90033-2

[10] Kipp, M. E., Sih, G. C. "The strain energy density failure criterion applied to notched elastic solids." International Journal of Solids and Structures, 11, pp. 153-173. 1975. https://doi.org/10.1016/0020-7683(75)90050-5

[11] Sih, G. C. "Some basic problems in fracture mechanics and new concepts." Engineering Fracture Mechanics. 5, pp. 365-377. 1973. https://doi.org/10.1016/0013-7944(73)90027-1

[12] Jayatilaka, A. S., Jenkins, I. J., Prasad, S. V. "Determination of crack growth in a mixed mode loading system." In: Taplin D. M. R (ed.) Analysis and Mechanics. (pp. 15-23.) Pergamon, 1978.

[13] Boulenouar, A., Benseddiq, N., Mazari, M. "Strain energy density prediction of crack propagation for 2D linear elastic materials." Theoretical and Applied Mechanics. 67-68, pp. 29-37. 2013. https://doi.org/10.1016/j.tafmec.2013.11.001

[14] Boulenouar, A., Benseddiq, N., Mazari, M., Benamara, N. "FE model for linear elastic mixed mode loading: estimation of SIFs and crack propagation." Journal of Theoretical and Applied Mechanics. 52, pp. 373-383. 2014.

[15] Boulenouar, A., Benouis, A., Benseddiq, N. "Numerical modelling of crack propagation in cement PMMA: Comparison of different criteria." Material Research. 19(4), pp. 846-855. 2016. https://doi.org/10.1590/1980-5373-MR-2015-0784 
[16] Benouis, A., Boulenouar, A., Benseddiq, N., Serier, B. "Numerical analysis of crack propagation in cement PMMA: application of SED approach." Structural Engineering and Mechanics. 55, pp. 93-109. 2015. https://doi.org/10.12989/sem.2015.55.1.093

[17] Benamara, N., Boulenouar, A., Aminallah, M., Benseddiq, N. "On the mixed-mode crack propagation in FGMs plates: Comparison of different criteria." Structural Engineering and Mechanics. 615(3), pp. 371-379. 2017.

[18] Ayatollahi, M. R., Sedighiani, K. "Mode I fracture initiation in limestone by strain energy density criterion." Journal of Theoretical and Applied Mechanics. 57, pp. 14-18. 2012. https://doi.org/10.1016/j.tafmec.2011.12.003

[19] Pegorin, F., Kotousov, A., Berto, F., Swain, M. V., Sornsuwan, T. "Strain energy density approach for failure evaluation of occlusal loaded ceramic tooth crowns." Journal of Theoretical and Applied Mechanics. 5, pp. 44-50. 2012.

https://doi.org/10.1016/j.tafmec.2012.02.006

[20] Benamara N., Boulenouar A., Aminallah M. "Strain Energy Density Prediction of Mixed-Mode Crack Propagation in Functionally Graded Materials." Periodica Polytechnica Mechanical Engineering. 61(1), pp. 60-67. 2017.

https://doi.org/10.3311/PPme.9682

[21] Komori, K. "Ductile fracture criteria for simulating shear by node separation method." Journal of Theoretical and Applied Mechanics. 43, pp. 101-114. 2005. https://doi.org/10.1016/j.tafmec.2004.12.006

[22] Chow, C. L., Xu, J. "Application of the strain energy density criterion to ductile fracture." Journal of Theoretical and Applied Mechanics. 3, pp. 185-191. 1985.

https://doi.org/10.1016/0167-8442(85)90029-1

[23] Carpinteri, A. "Size effects in material strength due to crack growth and material non-linearity." Journal of Theoretical and Applied Mechanics. 2, pp. 39-45. 1984. https://doi.org/10.1016/0167-8442(84)90038-7

[24] Boulenouar, A., Benseddiq, N., Merzoug, M., Benamara, N., Mazari, M. "A strain energy density theory for mixed mode crack propagation in rubber-like materials." Journal of Theoretical and Applied Mechanics. 54(4), pp. 1417-1431. 2016.

https://doi.org/10.15632/jtam-pl.54.4.1417

[25] Hamdi, A., AïtHocine, N., NaïtAbdelaziz, M., Benseddiq, N. "Fracture of elastomers under static mixed mode: the strain-energy-density factor." International Journal of Fracture. 144, pp. 65-75. 2007. https://doi.org/10.1007/s10704-007-9080-7

[26] Torabi, A. R., Campagnolo, A., Berto, F. "Tensile fracture analysis of V-notches with end holes by means of the local energy." Physical Mesomechanics. 18(3), pp. 194-202. 2015. https://doi.org/10.1134/S1029959915030030

[27] Berto, F., Campagnolo, A., Chebat, F., Cincera, M., Santini, M. "Fatigue strength of steel rollers with failure occurring at the weld root based on the local strain energy values: modelling and fatigue assessment." International Journal of Fatigue. 82, pp. 643-657. 2016. https://doi.org/10.1016/j.ijfatigue.2015.09.023

[28] Campagnolo, A., Berto, F., Leguillon, D. "Fracture assessment of sharp V-notched components under Mode II loading: a comparison among some recent criteria." Theoretical and Applied Fracture Mechanics. 85B, pp. 217-226. 2016.

https://doi.org/10.1016/j.tafmec.2016.02.001
[29] Pook, L. P., Campagnolo, A., Berto, F., Lazzarin, P. "Coupled fracture mode of a cracked plate under anti-plane loading." Engineering Fracture Mechanics, 134, pp. 391-403. 2015.

https://doi.org/10.1016/j.engfracmech.2014.12.021

[30] Pook, L. P., Campagnolo, A., Berto, F. "Coupled fracture modes of discs and plates under anti-plane loading and a disc under in-plane shear loading." Fatigue and Fracture of Engineering Materials and Structures. 39(8), pp. 924-938. 2016.

https://doi.org/10.1111/ffe.12389

[31] Berto, F., Ayatollahi, M. R., Campagnolo, A. "Fracture tests under mixed mode I+III loading: An assessment based on the local energy." International Journal of Damage Mechanics. 26(6), pp. 881-894. 2017. https://doi.org/10.1177/1056789516628318

[32] Mirsayar, M. M., Berto, F., Aliha, M. R. M., Park, P. "Strain-based criteria for mixed-mode fracture of polycrystalline graphite." Engineering Fracture Mechanics. 156, pp. 114-123. 2016. https://doi.org/10.1016/j.engfracmech.2016.02.011

[33] Radaj, D., Berto, F., Lazzarin, P. "Local fatigue strength parameters for welded joints based on strain energy density with inclusion of small-size notches." Engineering Fracture Mechanics. 76(8), pp. 1109-1130. 2009. https://doi.org/10.1016/j.engfracmech.2009.01.009

[34] Lazzarin, P., Livieri, P., Berto, F., Zappalorto, M. "Local strain energy density and fatigue strength of welded joints under uniaxial and multiaxial loading." Engineering Fracture Mechanics. 75(7), pp. 1875-1889. 2008. https://doi.org/10.1016/j.engfracmech.2006.10.019

[35] Berto, F., Gallo, P., Lazzarin, P. "High temperature fatigue tests of un-notched and notched specimens made of 40CrMoV13. 9 steel." Materials and Design. 63, pp. 609-619. 2014. https://doi.org/10.1016/j.matdes.2014.06.048

[36] Berto, F., Campagnolo, A., Lazzarin, P. "Fatigue strength of severely notched specimens made of Ti-6Al-4V under multiaxial loading." Fatigue and Fracture of Engineering Materials and Structures. 38(5), pp. 503-517. 2015 https://doi.org/10.1111/ffe.12272

[37] Lazzarin, P., Berto, F., Zappalorto, M. "Rapid calculations of notch stress intensity factors based on averaged strain energy density from coarse meshes: theoretical bases and applications." International Journal of Fatigue. 32(10), pp. 559-1567. 2010. https://doi.org/10.1016/j.ijfatigue.2010.02.017

[38] Pook, L. P., Berto, F., Campagnolo, A., Lazzarin, P. "Coupled fracture mode of a cracked disc under anti-plane loading." Engineering Fracture Mechanics. 128, pp. 22-36. 2014. https://doi.org/10.1016/j.engfracmech.2014.07.001

[39] Campagnolo, A., Berto, F., Lazzarin, P. "The effects of different boundary conditions on three-dimensional cracked discs under anti-plane loading." European Journal of Mechanics and Solids. 50, pp. 76-86. 2015. https://doi.org/10.1016/j.euromechsol.2014.11.001

[40] Sih, G. C., Barthelemy, B. M. "Mixed mode fatigue crack growth predictions." Engineering Fracture Mechanics. 13, pp. 439-51. 1980. https://doi.org/10.1016/0013-7944(80)90076-4

[41] Gdoutos, E. E. "Fracture mechanics." Solid Mechanics and its Applications, Vol. 123, Springer Netherlands., 2005. https://doi.org/10.1007/1-4020-3153-X

[42] Fajdiga, G., Ren, Z., Kramar, J. "Comparison of virtual crack extension and strain energy density methods applied to contact surface crack growth." Engineering Fracture Mechanics. 74, pp. 2721-2734. 2007. https://doi.org/10.1016/j.engfracmech.2007.01.016 
[43] ANSYS, Inc. "Programmer's Manual for Mechnical APDL." Release 12.1. 2009.

[44] Barsoum, R. S. "On the use of isoparametric finite element in linear fracture mechanics." International Journal for Numerical Methods in Engineering. 10, pp. 25-37. 1974.

https://doi.org/10.1002/nme.1620100103

[45] Blaise, A. "Caractérisation microstructurale d'un PEHD semicristallin déformé par tomographie $\mathrm{X}$ et diffusion de lumière polarisée." (Microstructural characterization of X-ray deformed semi-crystalline HDPE and polarized light scattering.) PhD Dissertation, University of Henri Poincaré, France, 2011. (in French)
[46] Benhemna, A., Aminallah, L., BachirBouiadjra, B., Benguediab, M., Amrouche, A., Benseddiq, N. "J integral solution for semi-elliptical surface crack in high density poly-ethylene pipe under bending." Materials and Design. 32, pp. 2561-2569. 2011.

https://doi.org/10.1016/j.matdes.2011.01.045

[47] Adib, A., Domínguez, C., García, R. A., Garrido, M. A., Rodríguez, J., "Influence of specimen geometry on the slow crack growth testing of HDPE for pipe applications." Polymer Testing. 48, pp. 104-110. 2015. https://doi.org/10.1016/j.polymertesting.2015.09.012 